\section{Rotten to the core}

\section{New Delhl}

THE way research is being conducted in Indian universities should be a cause of grave concern to scientists and planners alike, according to a new study from the Council of Scientific and Industrial Research. The study says the malaise is so deep rooted that it would take at least a decade to rejuvenate university research.

The study, entitled Quality, Character and Efficiency of Scientific Research in Universities and Indian Institutes of Technology, was directed by Professor Rais Ahmed, former chairman of the University Grants Commission. It is based on questionnaires given to supervisors and scholars in 27 selected institutions, including the five Indian Institutes of Technology, and six central and 16 state universities. In all, 824 professors and readers and 1,740 scholars responded. Analysis of the data reveals poor academic performance and frequent complaints of malpractice and unfair procedures.

The study shows that more than half of top-ranking students do not go into research. Those who do tend to come from poor backgrounds and lack motivation or enthusiasm. Eighty per cent of scholars have knowledge confined to their subject and half are "unable to read scientific literature or write a report".

There is very little guidance or supervision of university research, says the study. Supervision is on a casual basis and, in 80 per cent of universities, meetings between scholar and supervisor take place less than once a year. Forty per cent of supervisors do not actively participate in research or check experimental data.

The research environment in the universities is sadly undermined by prejudice and malpractice. The study says that scholars are assessed not on merit but on the basis of factors such as sex, caste, religion or the the part of the country they come from. "The sum total of prejudice must be acting like poison to the atmosphere in the lab", the report says. Academic research is also tarnished by malpractice such as the manipulation and forging of data or the award of degrees in spite of critical reports from examiners. Between 30 and 50 per cent of scholars said they were aware of malpractice. "These dishonourable practices are more common than one would have thought", the report says.

Academic values are also found to be lacking. Internal examinations fail properly to discriminate between good, indifferent and bad scholars. At least 40 per cent of supervisors think fit to recommend the award of doctorates to students whose theses were based on "unsound concepts or wrong methodology". Universities also suffer from too much inbreeding. As many as 90 per cent of faculty vacancies are filled from within.

One reason for the dismal atmosphere in the universities is poor funding, according to the report. The universities are the largest single research sector and employ 30 per cent of India's scientists and half of its $\mathrm{PhDs}$ but receive only six per cent of the national research and development budget. The universities have been left to vegetate and their work "is not closely examined, analysed or planned" by any

\title{
1-800-GOTOMARS
}

\section{Washington}

REMEMBER nuclear rockets? Anti-matter drives, solar sails, electromagnetic propulsion systems? Twenty years ago, at the height of the Apollo era, far-fetched plans for interplanetary travel were all the rage. The US National Aeronautics and Space Administration (NASA) is hoping that those kinds of ideas are still around. Last month it announced a $\$ 4.5$ million programme to scour the country for better ways to reach Mars - better, hopefully, than the $\$ 500,000$ million plan NASA put together last year after President George Bush backed Mars as the space agency's next goal.

Last week, Richard Truly, administrator of NASA, sent out 3,200 'personal' letters to presidents of universities, heads

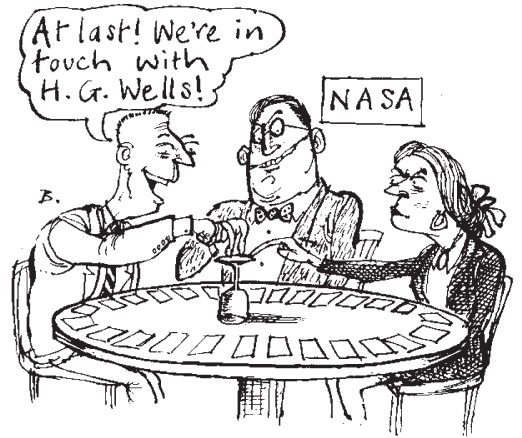

of research institutes and individual scientists in the United States, asking them to propose new "architectures", propulsion systems or materials for the Mars Mission. Truly does not want to hear from just the usual scientists; his offer is open to everyone from backyard inventors to teenage science wizards.

Operators at a 24-hour, seven-days-aweek toll-free number (1-800-677-7796 in the United States) are waiting to send out packages to help budding space planners send in their ideas.

Truly has appointed Thomas Stafford, a former astronaut, to lead a 'synthesis group' which will review incoming ideas and make recommendations as to which should be pursued further. One idea internal or external forum.

Universities urgently need funds, but money alone cannot change them without a radically different educational pattern, says the study. It is suggested that eight regional institutions be established with a new pattern of undergraduate and postgraduate education for which students will be selected by a national talent search. Universities need also to be persuaded to admit only research scholars screened through a nationally administered test. The whole system needs to be rebuilt, small cosmetic changes will not help, the study concludes.

K. S. Jayaraman
Stafford's panel already has on its table is for an inflatable spacecraft designed by Lowell Wood, the scientist at Lawrence Livermore National Laboratory who invented 'Brilliant Pebbles'. Wood's long, gas-filled plastic tubes (quickly dubbed 'Brilliant Condoms') have come in for criticism, but Vice-President Dan Quayle was said to have been impressed. Earlier this year he directed NASA to search for more innovative concepts for space travel (see Nature 343, 301; 25 January 1990).

NASA's 'outreach programme' may turn up good ideas that would otherwise fall between the cracks, or never be raised at all, according to John Pike, a space analyst at the Federation of American Scientists. "They may not have the depth of analysis or the breadth of proponancy" of an idea generated at NASA, he says, "but there may be something out there with some technical credibility that will allow NASA to do it cheaper." The problem is that any idea from outside NASA is unlikely to include a healthy role for all the NASA laboratories, something that Pike says has become an unstated prerequisite for the space agency's internal proposals. Pike intends to do his part and submit a proposal for a nuclearrocket scheme that he first developed as a high-school science project and which, he claims, still makes sense.

Imaginative contributors should probably forget any thoughts of profit or even much fame. NASA says it wants "concepts", not specific products. Proprietary technology or anything patented is unwelcome for now. "We're trying to look at the big picture", said NASA exploration head Arnold Aldrich. The American Institute of Aeronautics and Astronautics is also to survey the aerospace industry for new ideas, and NASA will review research at the federal laboratories. "We want to make sure we're plugged in to what's available", said Truly at a press conference.

G. Christopher Anderson 